Arq. Bras. Med. Vet. Zootec., v.56, n.4, p.558-561, 2004

\title{
Comunicação
}

[Communication]

\section{Mesotelioma pleural com metástase renal em gato}

[Pleural mesothelioma with renal metastasis in a cat]

\author{
A.M. Piacenti, N.M. Ocarino, A.E. Silva, M.A. Rachid, S.A. França, R. Serakides* \\ Escola de Veterinária UFMG \\ Caixa Postal 567 \\ 30123-970 - Belo Horizonte, MG
}

O mesotelioma é uma neoplasia originária das células mesodérmicas que revestem as cavidades pleural, pericárdica e peritoneal (Tilley et al., 1975; Meulten, 2002) e também a túnica vaginal do testículo (Thrall e Goldschmidt, 1978). São tumores raros nos animais domésticos e têm sido descritos em bovinos e cães (Stepien et al., 2000) e, com menor freqüência, em eqüinos, suínos e gatos (Head, 1990).

A etiologia do mesotelioma ainda não foi completamente elucidada. No homem existe relação direta entre a inalação crônica de partículas de amianto e a incidência de mesotelioma pleural (Raflo e Nuernberger, 1978; Bhandarkar et al., 1993). No bovino o mesotelioma pode ser congênito (Pizzarro et al., 1992) e em cães é de ocorrência espontânea (Andrews, 1973).

Macroscopicamente o mesotelioma caracterizase por múltiplos nódulos de consistência firme, com 0,1 a $5 \mathrm{~cm}$ de diâmetro, amarronzado a róseo, localizados nas serosas parietal e/ou visceral (Umphlet e Bertoy, 1988).

Os sinais clínicos ocorrem conseqüentes à presença da massa e ao acúmulo de líquido nas cavidades torácica e peritoneal, culminando com cianose e aumento da freqüência respiratória (Stepien et al., 2000). O tratamento do mesotelioma é paleativo e visa minimizar os sinais clínicos pela toracocentese e laparocentese, tendo em vista que a exérese

Recebido para publicação em 17 de outubro de 2003

Recebido para publicação, após modificações, em 1 de março 2004

E-mail: serakide@dedalus.lcc.ufmg.br completa da neoplasia geralmente é inviável (Umphlet e Bertoy, 1988).

A diferenciação entre mesotelioma e carcinomas primários dos tratos digestivo, genital ou urinário com metástase no peritônio e com o mesotélio reativo ou carcinomatoso pode ser difícil (Head, 1990), e necessita de exame anatomopatológico associado à imunoistoquímica. Contudo, as características imunoistoquímicas do mesotelioma dos animais domésticos têm sido pouco descritas (Serakides et al., 2001).

O objetivo deste trabalho é relatar e discutir os achados anatomopatológicos e imunoistoquímicos de um caso de mesotelioma pleural com metástase renal em um gato, sem raça definida, fêmea de oito anos de idade. Após a morte, o animal foi levado sem histórico clínico para o setor de patologia.

À necropsia, foram observados múltiplos nódulos esbranquiçados, de superfície lisa, firmes, variando de 2 a $3 \mathrm{~cm}$ de diâmetro, distribuídos difusamente e de forma restrita às pleuras parietal e visceral, pericárdio parietal (Fig. 1a) e porção torácica do diafragma. No córtex do rim esquerdo foi observado um nódulo saliente, esbranquiçado, com aproximadamente $1 \mathrm{~cm}$ de diâmetro, sugestivo de metástase. Não foram evidenciadas alterações macroscópicas nos linfonodos das cavidades pleural e abdominal.

Fragmentos dos nódulos e do rim acometido foram colhidos e fixados em formalina a $10 \%$ 
neutra e tamponada e processados pela técnica de inclusão em parafina e coloração pela hematoxilina-eosina. Os cortes também foram submetidos à análise imunoistoquímica, utilizando-se os seguintes anticorpos nas diluições apropriadas: anti-célula mesotelial, anti-célula epitelial, anti-vimentina e anticitoqueratina $^{1}$. O complexo estreptavidinabiotina-peroxidase $^{1}$ e a diaminobenzidina ${ }^{2}$ foram utilizados para detecção dos antígenos. Secções foram contra-coradas com hematoxilina de Harris.

Microscopicamente observou-se proliferação de células neoplásicas dispostas em túbulos irregulares e de tamanhos variados. Estes túbulos eram revestidos por uma ou mais camadas de células que formavam projeções papiliformes em direção ao lúmen (Fig. 1b). As células neoplásicas eram cúbicas, com citoplasma ora eosinofílico ora claro, núcleo oval a arredondado, denso ou vesiculoso, contendo nucléolos proeminentes. Foram evidenciadas raras figuras de mitose e anisocitose moderada. No lúmen de alguns túbulos havia material eosinofílico e amorfo com debris celulares. As células neoplásicas apresentavam-se envoltas por moderada quantidade de tecido conjuntivo bem vascularizado. Notou-se ainda áreas multifocais de necrose e infiltrado de células inflamatórias mononucleares, representadas predominantemente por linfócitos. No córtex renal observouse proliferação focal de células neoplásicas com as mesmas características descritas anteriormente (Fig. 1c) e com área central de necrose.

O sumário dos resultados da imunoistoquímica estão na Tab. 1. O citoplasma das células neoplásicas apresentou expressão forte e difusa das citoqueratinas AEI e AE3 (Fig. 1d) e expressão forte e multifocal de vimentina (V9) (Fig. 1e). A membrana e o citoplasma das células neoplásicas apresentaram reação positiva para o anticorpo contra célula mesotelial humana (HBME-1) com marcação multifocal ora intensa, ora discreta (Fig. 1f). Não foi observada marcação para o antígeno epitelial de membrana (EMA).

Alguns anticorpos são utilizados, com sucesso na diferenciação entre mesotelioma e adenocarcinoma, dentre eles o HBME-1 (anticélula mesotelial humana) e o EMA (antiantígeno epitelial) (Riera et al., 1997; Alves et al., 1999; Serakides et al., 2001). Apesar de as células mesoteliais neoplásicas no homem apresentarem marcação para o HBME 1, esse marcador não é específico para o mesotelioma, já que uma porcentagem elevada de adenocarcinomas também são imunorreativos (Bateman et al., 1997). Contudo, o anti-célula mesotelial humana marca predominantemente a membrana das células neoplásicas no mesotelioma, enquanto no adenocarcinoma a marcação é intracitoplasmática. $\mathrm{O}$ antígeno embrionário de membrana geralmente não é expresso nas células mesoteliais, ao contrário do que ocorre nos carcinomas. $\mathrm{O}$ padrão imunoistoquímico descrito para o mesotelioma humano é similar ao do presente caso, possibilitando firmar o diagnóstico definitivo de mesotelioma com metástase renal.

Histologicamente, o mesotelioma pode ser classificado como epitelial, sarcomatoso e bifásico, sendo este último o padrão mais freqüentemente observado em animais (Pizzaro et al., 1992). As características histológicas associadas à co-expressão de vimentina e citoqueratina permitiram caracterizar a neoplasia como bifásica, ou seja, com a presença de células epiteliais e mesenquimais.

Com base nos achados anatomopatológicos e imunoistoquímicos firmou-se o diagnóstico de mesotelioma pleural bifásico com metástase renal.

Palavras-chave: gato, mesotelioma, pleura, imunoistoquímica

\footnotetext{
${ }^{1}$ Dako, USA

${ }^{2}$ DAB - Substrate System, Lab Vision
} 

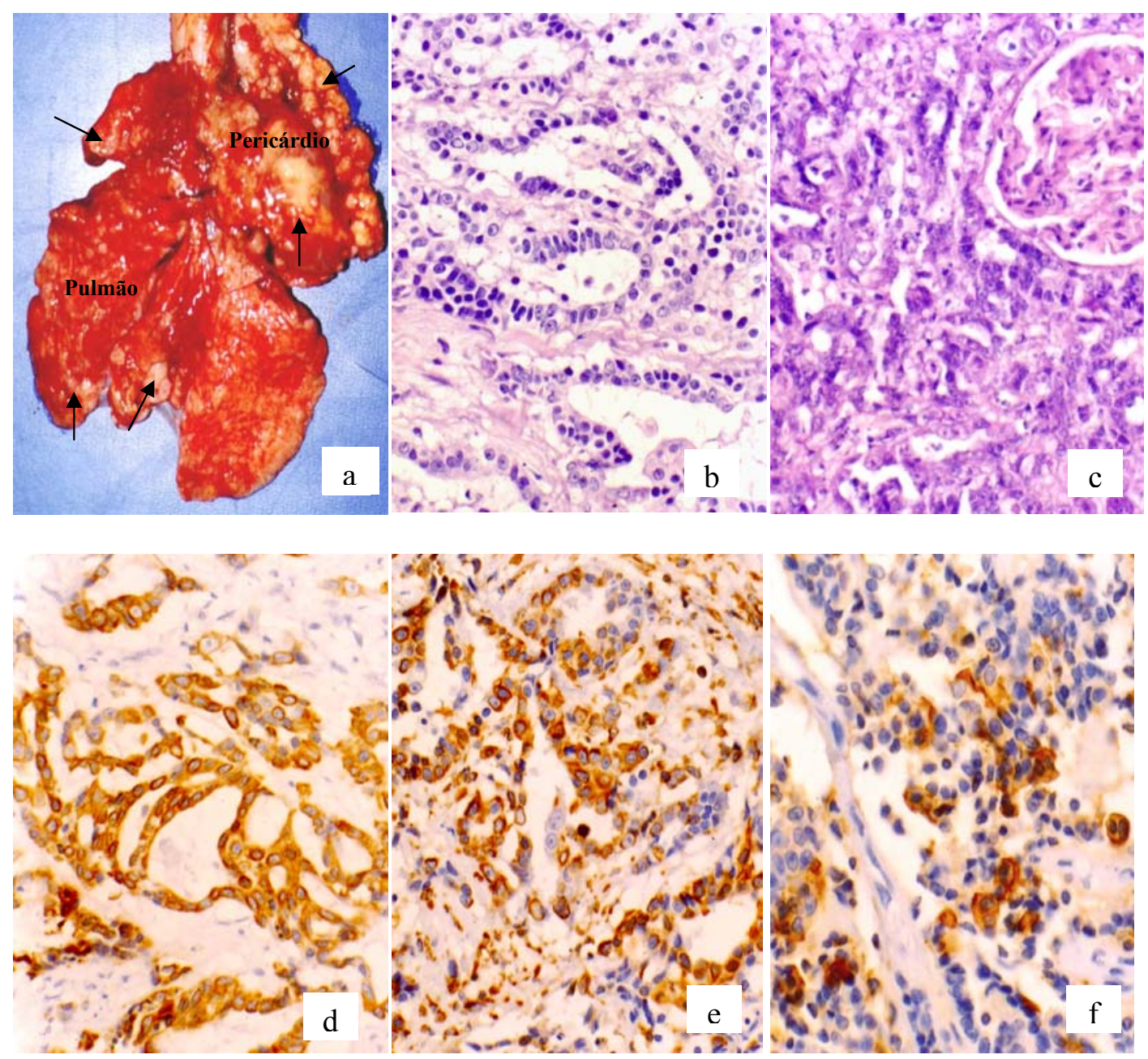

Figura 1.Gato, mesotelioma. a) Múltiplos nódulos esbranquiçados distribuídos difusamente na pleura visceral e pericárdio parietal (setas). b) Proliferação de células neoplásicas dispostas em túbulos irregulares e de tamanhos variados revestidos por uma ou mais camadas de células formando projeções papiliformes em direção ao lúmen. No lúmen de alguns túbulos, havia debris celulares. HE, 429×. c) Córtex renal com proliferação focal de células neoplásicas com as mesmas características da neoplasia primária. HE, 321×. d) Citoplasma das células neoplásicas com expressão forte e difusa das citoqueratinas AEI e AE3. Estreptavidina-biotina-peroxidase, hematoxilina de Harris, 429×. e) Expressão forte e multifocal de vimentina nas células neoplásicas e no interstício. Estreptavidina-biotina-peroxidase, hematoxilina de Harris, 429×. f) Reação positiva multifocal intensa para o anticorpo contra célula mesotelial humana (HBME-1). Estreptavidina-biotina-peroxidase, hematoxilina de Harris, 604×.

Tabela 1. Reação imunoistoquímica do mesotelioma pleural em gato

\begin{tabular}{lcc}
\hline Anticorpo & Clone & Célula mesotelial neoplásica \\
\hline Anti-vimentina & V9 & Positiva com reação forte e multifocal \\
Anti-citoqueratina & AE1/AE3 & Positiva com reação forte e difusa \\
Anti-cél. mesotelial humana & HBME-1 & Positiva com focos de reação fraca e focos fortes e multifocal \\
Anti-antígeno epitelial & EMA & Negativa \\
\hline
\end{tabular}




\begin{abstract}
It has been described the anatomopathological and immunohistochemical characteristics of a multinodular neoplasm distributed in the parietal and visceral pleurae, pericardium, thoracic portion of the diaphragm and renal cortex of an eight year-old, female, mixed breed, cat. Based on the anatomopathological and immunohistochemical findings it was firmed the diagnosis of biphasic pleural mesotelioma with renal metastasis.
\end{abstract}

Keywords: cat, mesothelioma, pleura, immunohistochemistry

\section{REFERÊNCIAS BIBLIOGRÁFICAS}

ALVES, V.A.F.; BACCHI, C.E.; VASSALLO, J. Manual de imuno-histoquímica. São Paulo: Sociedade Brasileira de Patologia, 1999. 270p.

ANDREWS, E.J. Pleural mesothelioma in a cat. J. Comp. Pathol., v.83, p.259-263, 1973.

BATEMAN, A.C.; AL-TALIB, R.K.; NEWMAN, T. et al. Immunohistochemical phenotype of malignant mesothelioma: predictive value of CA125 and HBME-1 expression. Histopathology, v.30, p.49-56, 1997.

BHANDARKAR, D.S.; SMITH, V.J.; EVANS, D.A. et al. Benign cystic peritoneal mesothelioma. J. Clin. Pathol., v.46, p.867-868, 1993.

HEAD, K.W. Tumors of the alimentary tract. In: Tumors of domestic animals. 3.ed. Berkeley: University of California, 1990. p.422-427.

MEUTEN, D.J. Tumors in domestic animals. 4.ed. Iowa State: University of California, 2002. $788 \mathrm{p}$.

PIZARRO, M.; BRANDAU, C.; SANCHES, M.A. et al. Immunocytochemical identification of a bovine peritoneal mesothelioma. J. Vet. Med., v.39, p.476-480, 1992.
RAFLO, C.P.; NUERNBERGER, S.P. Abdominal mesothelioma in a cat. Vet. Pathol., v.15, p.781- 783, 1978.

RIERA, J.R.; ASTENGO-OSUNA, C.; LONGMATE, J.A. et al. The immunohistochemical dignostic panel for epithelial mesothelioma: a reevaluation after heat-induced epitope retrieval. Am. J. Surg. Pathol., v.21, p.1409-1419, 1997.

SERAKIDES, R.; CASSALI, G.D.; SANT'ANA, F.J.F. et al. Mesotelioma peritoneal em cão: relato de caso. Arq. Bras. Med. Vet. Zootec., v.53, p.183-187, 2001.

STEPIEN, R.L.; WHITLEY, N. T.; DUBIELZIG, R.R. Idiopathic or mesotheliomarelated pericardial effusion: clinical findings and survival in 17 dogs studied retrospectively. $J$. Small Anim. Pract., v.41, p.342-347, 2000.

THRALL, D.E.; GOLDSCHMIDT, M.H. Mesothelioma in the dog: six case reports. J. Am. Vet. Rad. Soc., v.19, p.107-114, 1978.

TILLEY,L.P.; OWENS, J.M.; WILKINS, R.J. et al. Pericardial mesothelioma with effusion in a cat. J. Am. Anim. Hosp. Assoc., v.11, p.60-65, 1975.

UMPHLET, R.C.; BERTOY, R.W. Abdominal mesothelioma in a cat. Mod. Vet. Pract., v.69, p.71-71, 1988. 